\title{
Monitoring implementation of the Tokyo Convention on recognition: a multi-stakeholder approach to the internationalization of higher education in the Asia-Pacific
}

\author{
Wesley R. Teter and Libing Wang \\ UNESCO Asia and Pacific Regional Bureau for Education, Bangkok, Thailand
}

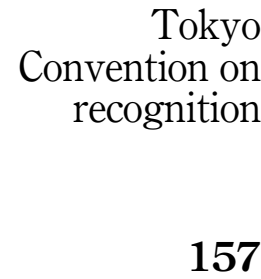

Received 31 October 2020 Revised 1 February 2021 Accepted 8 February 2021

\begin{abstract}
Purpose - The impacts of the COVID-19 pandemic have transformed the global outlook for international higher education. Given the rapid shift to online learning, the Tokyo Convention in the Asia-Pacific entrusted to UNESCO has become an important policy framework to facilitate regional collaboration, authoritative information sharing and recognition of qualifications across diverse modes of learning. This paper examines the role of the Tokyo Convention to establish an inclusive platform for monitoring and collaborative governance of mobility and internationalization based on fair and transparent recognition policies and practices in the Asia-Pacific.

Design/methodology/approach - In August 2019, a standardized survey instrument was sent by the Secretariat of the Tokyo Convention Committee at UNESCO Bangkok to competent recognition authorities in 46 countries in the Asia-Pacific, including the eight State Parties to the Tokyo Convention that ratified the Convention as of the reporting period. In total, qualitative data from $n=27$ countries/states was received and analyzed to assess implementation of the Tokyo Convention throughout the region. The research design illustrates how normative instruments such as the Tokyo Convention are monitored and assessed over time. Findings - A multi-stakeholder approach based on collaborative governance is needed to effectively monitor implementation and implications of the Tokyo Convention for diverse higher education stakeholders in the Asia-Pacific region.

Research limitations/implications - Implications include establishing baseline data and methods for monitoring implementation of the Tokyo Convention. Based on collaborative governance theory, the paper explores potential for a multi-stakeholder approach to promote mutual accountability in the Asia-Pacific and to develop mechanisms for inclusive participation in the governance of the forthcoming Global Convention on recognition.

Originality/value - As the first systematic review of its kind, this paper includes a unique dataset and insights into UNESCO'S methodology to monitor implementation of standard-setting instruments for qualifications recognition in the Asia-Pacific.
\end{abstract}

Keywords Tokyo convention, Mutual recognition, Mobility, SDG4

Paper type Technical paper

\section{Introduction}

The COVID-19 pandemic has disrupted education systems, training and international mobility at an unprecedented scale. Stakeholders worldwide have shifted to remote forms of learning, teaching and work, utilizing advances in technology and flexible approaches to ensure the

(C) Wesley R. Teter and Libing Wang. Published by Emerald Publishing Limited. This article is published under the Creative Commons Attribution (CC BY 4.0) licence. Anyone may reproduce, distribute, translate and create derivative works of this article (for both commercial and non-commercial purposes), subject to full attribution to the original publication and authors. The full terms of this licence may be seen at http://creativecommons.org/licences/by/4.0/legalcode

The authors wish to thank the editors and the Graduate School of Education at the University of Tokyo for financial support to make this article available as open access in line with UNESCO's Open Access Policy.

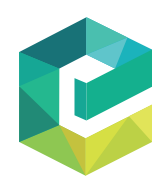

International Journal of Comparative Education and Development Vol. 23 No. 3, 2021 pp. $157-174$

Emerald Publishing Limited 2396-7404 DOI 10.1108/IJCED-10-2020-0075 
IJCED

23,3

158

continuity and quality of learning. Nevertheless, an estimated $40 \%$ of the poorest countries have not provided specific support to vulnerable learners during the COVID-19 crisis (UNESCO, 2020).

Given the growing diversity of education and training providers, modes of learning and level of disparities in quality assurance culture (Hou, 2012), there is an urgent need for collaboration to ensure fair and transparent recognition of qualifications. With a focus on cross-border higher education, this paper introduces normative instruments such as the regional and global conventions and explores their governance structures, monitoring practices and implications for qualifications recognition in the Asia-Pacific region. The aim is to assess gaps in policy implementation and potential for a multi-stakeholder approach based on collaborative governance.

\subsection{Internationalization to achieve quality higher education for all}

Internationalization is widely regarded as a multifaceted process of integrating an international dimension into the purpose and functioning of higher education systems (Knight, 2007). As part of Sustainable Development Goal Four (SDG4) and the Education 2030 Framework for Action, countries worldwide set a universal goal to achieve quality education, including equal access to affordable technical, vocational and higher education (SDG4.3) and expand higher education scholarships for developing countries (SDG4.b). The internationalization of higher education was prioritized as an effective means to promote access to global knowledge systems and to build capacity based on local needs (UNESCO, 2015a). In this regard, the importance of internationalization in promoting quality and access to higher education remains central to the concept itself.

After more than two decades of the rapid expansion of higher education, the Asia-Pacific region faces significant challenges for managing quality, particularly in development contexts where administrative systems are weak. International collaboration in the region is complicated by highly disparate national systems of governance, higher education institutional capacities and levels of development (Jarvis and Mok, 2019). Nevertheless, efforts to monitor and ensure quality are critical dimensions of international higher education systems (Altbach and Knight, 2007). Effective governance and monitoring mechanisms are needed to overcome persistent inequalities in learning and achieve sustainable development, including equitable access to quality higher education in line with SDG4.

As the only UN agency with a mandate in higher education, UNESCO has a unique role to play in coordinating SDG4. In the Asia-Pacific region, UNESCO Bangkok serves as Secretariat of the Asia-Pacific Regional Convention on the Recognition of Qualifications in Higher Education (Tokyo Convention), and its predecessor, the 1983 Convention (UNESCO, 1983, 2011). With the commencement of the Tokyo Convention on recognition on 1 February 2018, the decisionmaking structures around mobility and the recognition of qualifications continue to evolve. How, if at all, does the Tokyo Convention contribute to the governance and monitoring of cross-border mobility in the Asia-Pacific? What is the role of multi-stakeholder collaboration to facilitate fair and transparent recognition of diverse modes of learning? To address these questions, the following paper describes an underreported dimension of recognition policies and practices based on the legally-binding articles of the Tokyo Convention and data analyzed from recognition authorities in the region.

The next section explores the literature of mutual recognition and introduces the concept of collaborative governance. This includes background from the UNESCO Institute for Statistics on the current state of play for mobility and access-related issues in Asia and the Pacific. Based on analysis of the Tokyo Convention itself and data from country reports, the third section of this paper provides an overview of how the Convention is implemented in the AsiaPacific region. This includes analysis of three articles from the Tokyo Convention including 
how countries manage substantial differences, the status of National Information Centres (NIC), and how/if countries ensure qualifications assessments are accessible for all learners, including vulnerable learners in the Asia-Pacific.

\section{Mobility and the need for collaborative governance in the Asia-Pacific}

The role of quality assurance systems to underpin mutual recognition has received significant attention worldwide (Woodhouse, 1998, 2008), including in Europe (ECA, 2008), and more recently in Asia (Alam, 2019; Hou, 2012; Hou et al., 2017; Lee, 2012). Despite the unique role of normative instruments that deal with mutual recognition, there is limited awareness about their purpose and functions expect for the case of Europe (Knight, 2007).

Before elaborating on the governance and implementation status of the Tokyo Convention, this section introduces important cross-border mobility trends and an analytical framework from collaborative governance theory. Collaborative approaches to managing decision-making are increasingly recognized as a dominant frame of reference in public administration today (Ansell and Gash, 2008; Ansell and Torfing, 2016; Bryson et al., 2015; Emerson et al., 2011; Morse, 2011; Teter, 2020). In an important meta-analytical analysis, Ansell and Gash (2008), systematically reviewed 137 cases of collaborative governance across a range of policy sectors, including in public health, education, social welfare and international relations. Drawing on this work collaborative governance was defined as:

A governing arrangement where one or more public agencies directly engage non-state stakeholders in a collective decision-making process that is formal, consensus-oriented, and deliberative and that aims to make or implement public policy or manage public programs or assets. (Ansell and Gash, 2008, p. 544)

The definition included six important dimensions that serve as a lens to understand collaborative governance: (1) the forum was initiated by public agencies/institutions; (2) participants include nonstate actors; (3) participants engage in decision-making and are not only consulted; (4) the forum is formal and meets collectively; (5) the form aims to make decisions by consensus; and (6) the focus of collaboration is on policy or public management (Ansell and Gash, 2008). Collaborative governance provides an analytical framework to analyze stakeholder participation in the governance of the Tokyo Convention and potential gaps in policy and practice. Related propositions suggest that collaborations across sectors are more likely to be successful if they engage in regular assessments and have effective accountability systems in place (Bryson et al., 2015). To elaborate on these accountability systems, an important aim of the present research is to assess how collaborative governance is implemented and monitored in the context of the Tokyo Convention.

Addressing the importance of an inclusive approach to collaborative governance, this paper will review accountability mechanisms of the Tokyo Convention Committee such as the level of participation among diverse stakeholders and related implications for mobility and recognition. To establish a baseline of data, the following section explores the current situation of student mobility in the Asia-Pacific, including a brief overview of intra-regional and outbound mobility. These trends underline the importance of collaborative governance to effectively monitor the potential impact of the Tokyo Convention and assess implications for education access and equity in the Asia-Pacific. In other words, inclusive governance is based on an understanding of these baseline trends in the region.

\subsection{The growing demand for quality higher education in Asia-Pacific}

In the past several decades, the Asia-Pacific region has witnessed a significant expansion of higher education with important implications for social mobility (Marginson, 2018). From 1980 , the region has seen the tertiary age population (18-22 years old) grow on an average of
Tokyo
Convention on
recognition 
IJCED

23,3

160

$2.17 \%$ per year. Tertiary enrolment has seen an average growth of $13.8 \%$ per year, which is more than six times higher than the population growth for tertiary age population over the same time. Further, the tertiary gross enrolment ratio for the region was less than $6 \%$ in 1980 but in 2017, was above 35\% (Figure 1).

To meet growing demand, the role of private higher education institutions has increased significantly. Several countries in the Asia-Pacific have higher enrolments in the private sector than the public sector. For example, Japan and the Republic of Korea have a relatively high private higher education enrolment of approximately $80 \%$. Yet even with the expansion of public and private higher education, a significant proportion of youth do not have access to tertiary education in the Asia-Pacific region. Among 22 countries out of 37 countries $(60 \%)$ for which UIS data is available, more than $20 \%$ of the youth population (15-24 years old) are not in education, employment or training. This example illustrates significant gaps in the availability of data and, more importantly, youth access to education. Both issues are fundamental concerns for monitoring higher education systems effectively.

Further, most countries show that attending and completing higher education depends on family wealth and that completion rates for the poorest are significantly lower compared to the richest, pushing vulnerable groups to further marginalization (UIS, accessed 2 September 2019). The disparity between poor and rich is more prevalent in Eastern and South Eastern Asia compared to Central and Southern Asia region. These sub-regional trends in terms of equity, access and completion rates in higher education are important to explore.

Individuals from urban settings from rich families also have higher chances of attending and completing higher education compared to people from rural areas from poor family backgrounds. There are still significant gaps between urban and rural higher education attendance and completion. The lack of opportunities in rural areas for higher education is one potential factor for lower completion rates. Low enrolment and completion in basic and secondary education is also evident in rural areas that may also have a significant role in low attendance rates in higher education for rural areas. These factors may limit access to quality higher education. Cross-border mobility, including intra-regional mobility, is a related concern of equity and access to quality higher education.

\subsection{Cross-border student mobility in the Asia-Pacific}

Approximately half $(48 \%)$ of the world's outbound students are from the Asia-Pacific region. China and India have the most outbound mobile students in the region. North America and Western Europe receive the most students from Asia-Pacific; however, East Asia and the Pacific was the second choice for mobile students from Asia-Pacific for study (UIS, accessed September 2, 2019). Given increasing demand, this intra-regional mobility is likely to grow further.

Among the total outbound mobile students from the Asia-Pacific region, two-thirds are from five countries - China, India, Republic of Korea, Kazakhstan and Vietnam. Student mobility increased both for outbound as well as inbound students coming to East Asia and Pacific. Besides the large amount of outbound students, inbound students to East Asia and Pacific almost doubled from 2004 to 2017 (Figure 2). Most of the inbound students to East Asia and Pacific come from North America and Western Europe.

Next, the annual growth rate of selected countries (tertiary enrolment percentage) is compared to the outbound student percentage (Figure 3). For more than half of the countries included in the analysis, the rate of mobile outbound student has past the annual tertiary student growth rate at home (UIS, accessed September 2, 2019). This is a risk to domestic provision of quality higher education as more students seek opportunities abroad.

Given increased cross-border mobility and growing demand for quality higher education, the recognition of qualifications plays a central role to guide internationalization strategies with the aim to increase access and quality of higher education for all. Drawing on these 
Tokyo

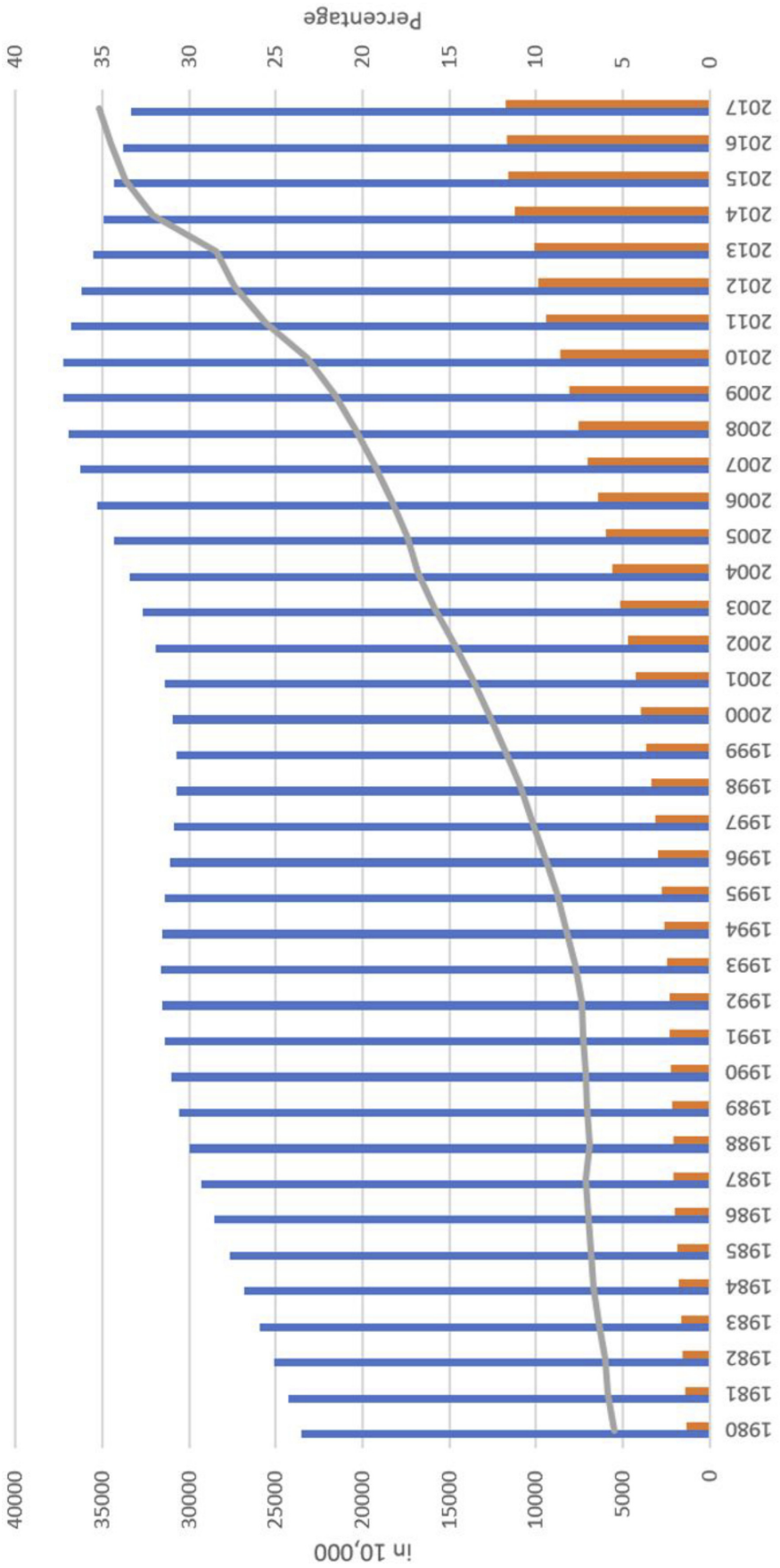

Convention on recognition

161

岀

है

Figure 1.

Significant expansion of tertiary education in the Asia-Pacific region 


\section{IJCED}

23,3

162

Figure 2.

Inbound students to

East Asia and Pacific almost doubled from 2004 to 2017

\section{Inbound Mobile students by region 2004}

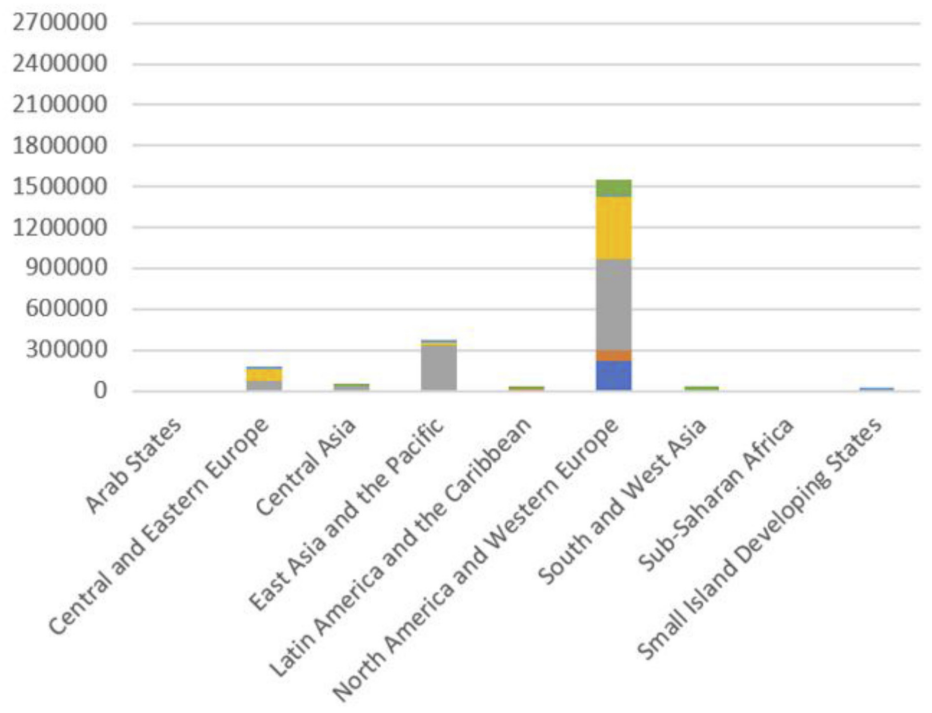

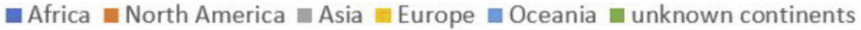

\section{Inbound Mobile students by region 2017}

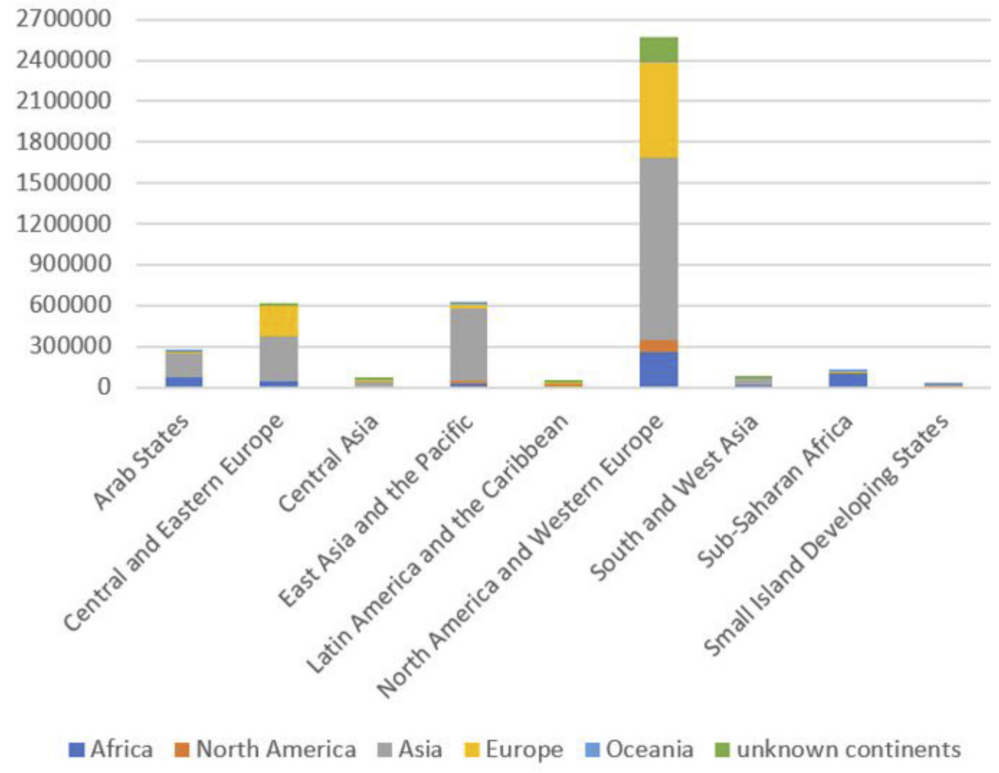

Source(s): UIS, accessed 2 September 2019 


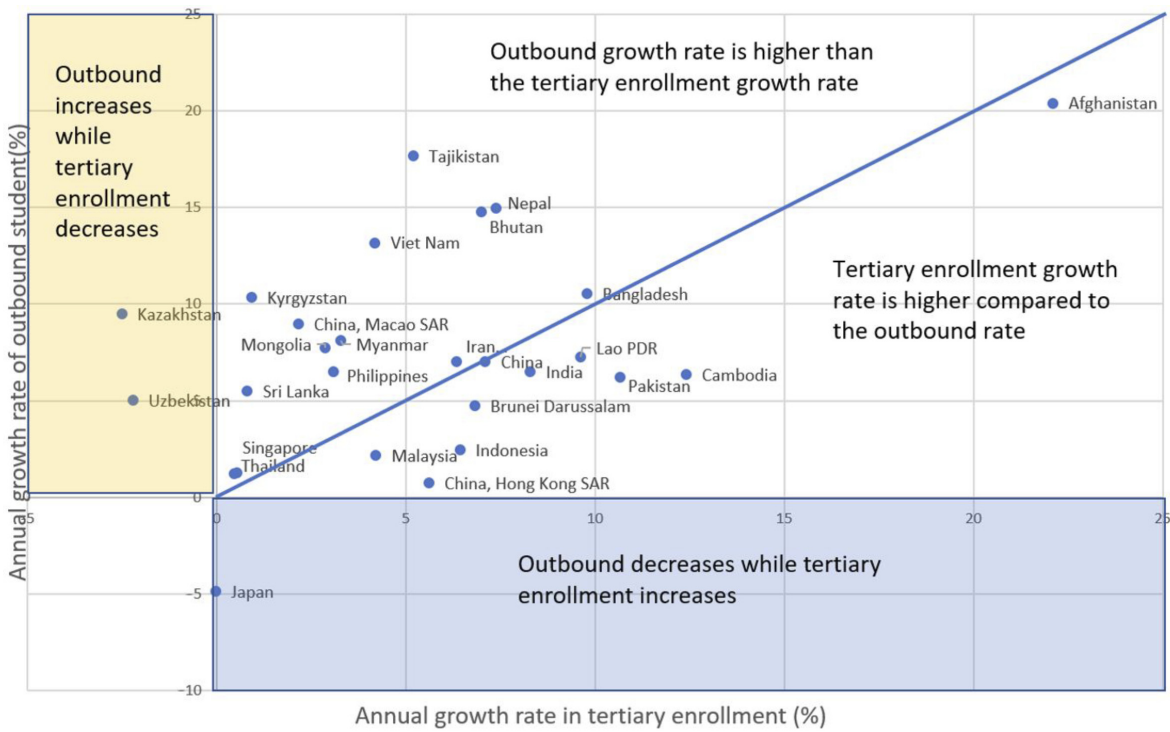

Source(s): UIS, accessed 2 September 2019

\section{Tokyo \\ Convention on recognition}

163

Figure 3.

Annual growth rates of selected countries: Outbound student \% vs tertiary enrolment $\%$

trends and underlying principles to ensure equitable access to quality higher education, the following section elaborates on the role of the Tokyo Convention and current means of monitoring its implementation in the Asia-Pacific region.

\section{Monitoring qualifications recognition in the Asia-Pacific}

The Tokyo Convention is a commitment by Parties to best principles and practices for the recognition of qualifications to support cross-border student mobility. The provision of authoritative information and international cooperation are essential for Parties to achieve their collective aims. Drawing on the six-part definition of collaborative governance put forward earlier by Ansell and Gash (2008), the Tokyo Convention is relatively well-aligned: (1) serving as a forum initiated by public agencies in the Asia-Pacific, (2) may include non-governmental organizations active in the field of recognition, (3) delegates engage in decision-making, (4) join formal committee sessions, (5) make decisions by consensus of the committee and (6) is focused on policies for recognition. The option to include or exclude non-governmental organizations is an important limitation that will be discussed later. First, this section elaborates on the governance structure of the Tokyo Convention and presents data on the current status of its implementation in the Asia-Pacific region as of September 2019.

Conceived within the framework of the modernization of the UNESCO Regional Conventions on the Recognition of Higher Education Qualifications, the Tokyo Convention is part of the second generation of the regional conventions, together with the Lisbon Convention and the Addis Convention in Europe and Africa, respectively. The revised convention for the Asia-Pacific region was adopted during an International Conference of States in Tokyo, Japan, in 2011 and entered into force after being ratified by the minimum of five Member States.

The Tokyo Convention's entry into force represented a landmark for the recognition of higher education qualifications in the Asia-Pacific region. During the First Session of the Tokyo Convention Committee in October 2018, governments endorsed the Seoul Statement, 
IJCED

23,3

164

acknowledging the Tokyo Convention was "a new era for mobility and internationalization of higher education in Asia-Pacific through qualifications recognition" (UNESCO, 2018b). Based on these broad aspirations, how the Convention is operationalized based on shared principles is critical to explore further.

The Tokyo Convention defines the recognition of qualifications as "means a formal acknowledgment as defined and given by the competent recognition authorities of a Party of the value of a foreign education qualification" (UNESCO, 2011, Article I). The Convention also promotes recognition of partial studies and of prior learning based on domestic regulatory requirements. The purpose is to reduce barriers to cross-border mobility including, but not limited to: the right to apply for admission to higher education; and/or the possibility to seek employment opportunities subject to domestic laws and regulations (UNESCO, 2011). Along these lines, the Convention supports information sharing among authorities and quality assurance agencies, which in turns helps to facilitate fair recognition of higher education qualifications and improve mobility governance in the Asia-Pacific region.

Drawing on official reports from September 2019, the following section presents data on the status of implementation of the Tokyo Convention based on core principles and Convention articles [1]. The evidence presented below illustrates implementation of the Convention among State Parties based on three areas: determining substantial differences among qualifications, developing an authoritative national information center and protecting the rights of vulnerable learners. Each of these three areas is important to understand the role of the Tokyo Convention and how limited stakeholder engagement may impact fair recognition policies and practices.

\subsection{Promoting evidence-based assessments and fair recognition}

The Tokyo Convention requires parties to make decisions on recognition based on appropriate information on the qualifications (i.e. fair and transparent recognition policies and practices). The Convention's standards encourage student mobility based on trust, mutual understanding, and information sharing. Education institutions are encouraged to provide within a reasonable timeframe relevant information to the holder of qualifications or the competent recognition authorities. An evidence-based assessment provides a framework of quality assurance for the fast-growing diversity of higher education providers, and further develops principles for fair recognition. To implement these principles, each party to the Tokyo Convention has the obligation to provide adequate and clear information on its education system.

During the 1st Session of the Tokyo Convention Committee in 2018, Member States agreed that: "a strong National Information Centre (NIC) is key to effective implementation of the Tokyo Convention as they promote mutual understanding and transparency of national education systems and qualifications" (UNESCO, 2018b). Each party agreed to take adequate measures for the development and maintenance of an NIC that will provide higher education information. The form of the NIC can vary (Tokyo Convention, Article VIII.3).

In line with the Convention, a new network for collaboration was established during the 2nd Session of the Tokyo Convention Committee in September 2019 called the Asia-Pacific Network of NICs (APNNIC) (UNESCO, 2019b). The APNNIC is charged with implementing the Convention, including core principles such as transparent, fair and shared norms for qualifications assessments in Asia-Pacific. The Convention ensures students have access to accurate information about different education systems, which can also help facilitate recognition of qualifications earned abroad. The right of appeal in the Convention protects the student's right to education fairness and against discrimination. How these benefits and obligations are understood and implemented at multiple levels by different stakeholders is important for how the Convention is monitored locally and regionally. 
3.2 Monitoring implementation of the Tokyo Convention on recognition

To monitor implementation, contracting States to the 1983 Convention agreed to submit reports to UNESCO every two years on the progress made and the obstacles encountered (1983 Convention, Article 10.2). The country report (one per country) is submitted by designated authorities to the Secretariat at UNESCO Bangkok. The survey structure and country report are standardized and designed to gather needed information on the 1983 Convention as well as to review each country's readiness and barriers to ratify and implement the Tokyo Convention on recognition. The survey was developed by UNESCO and refined by the Secretariat at UNESCO Bangkok based on the articles in the Convention.

To determine the status and readiness of a country's readiness to implement the Tokyo Convention, the survey focused on the following articles:

(1) Article II: Ensure competent recognition authorities implement the Convention;

(2) Article III: Make appropriate arrangements to assess qualifications (i.e. basic principles) in a manner that is transparent, coherent, reliable, fair, timely and non-discriminatory;

(3) Article IV, V and VI: Assess or recognize qualifications unless a substantial difference can be shown;

(4) Article VII: Make all reasonable efforts for refugee access;

(5) Article VIII: Provide relevant information, including developing and maintaining an NIC (UNESCO, 2011).

In total, 27 reports were received by UNESCO Bangkok by September 2019 (from eight parties to the Tokyo Convention, and 19 from non-state parties) (Table 1). Given the reports contain confidential information, care was taken to ensure no sensitive information or individuals/countries could be identified in the analysis. With a collaborative governance lens and focus on participation, implementation of three articles in the Tokyo Convention were analyzed: substantial differences (Article IV, V and VI), access to assessments for refugees (Article VII) and NICs (Article, VIII). Differences between parties and nonstate parties to the Tokyo Convention are discussed below. The selection of these three articles versus other areas was subjective and based on available data and the authors' professional understanding of how UNESCO's normative instruments enable cross-border mobility based on fairness and transparency.

(1) Substantial difference - Articles IV, V and VI of the Tokyo Convention require each party to assess, or recognize qualifications issued by other parties that give access to or were obtained unless a "substantial difference" can be shown. This includes the assessment of partial studies and recognition, where deemed appropriate. The Tokyo

\begin{tabular}{ll}
\hline Parties to the Tokyo Convention $\dagger$ & Non-state parties to the Tokyo Convention \\
\hline Eight (8) reports received & $\begin{array}{l}19 \text { reports received } \\
\text { Australia,* China,* Holy See, Japan, Mongolia,* }\end{array}$ \\
$\begin{array}{l}\text { Afghanistan, Bhutan, Kiribati, Kyrgyzstan*,Lao PDR*, } \\
\text { New Zealand, Republic of Korea,* and Turkey** }\end{array}$ & $\begin{array}{l}\text { Myanmar, Nauru, Nepal*, Papua New Guinea, } \\
\text { Philippines*, Samoa, Sri Lanka*, Thailand, Timor- } \\
\text { Leste, Tonga, Tuvalu, Uzbekistan, Vanuatu, Vietnam }\end{array}$
\end{tabular}

Note(s): *1983 State Parties

$\dagger$ Fiji ratified in October 2020 and did not submit a country report in 2019

Source(s): Authors

\section{Tokyo \\ Convention on recognition}

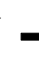


IJCED

23,3

\section{6}

Convention allows each party to define and interpret what constitutes a substantial difference. According to country reports for both parties and nonstate parties, most respondents $(81.4 \% ; n=22 / 27)$ do not have a nationally regulated definition. Instead, competent recognition authorities may interpret the term, or respondents reported their higher education systems have regulations at institutional level. Given the variance of systems and terminology, competing definitions around the term substantial difference is not explored here. The forthcoming Global Convention will introduce a new definition as will be discussed later in this article.

(2) Refugees and persons in a refugee-like situation - In line with the Tokyo Convention, respondents in Asia-Pacific were asked if their country had procedures to assess fairly and expeditiously whether refugees, displaced persons and persons in a refugee-like situation fulfil relevant requirements for access to higher education or recognition of qualifications (Tokyo Convention, Article VII). All parties to the Convention agreed to develop such procedures in principle, but only $62.5 \%$ of parties reported having procedures in place as of September 2019 (Table 2). Others did not have relevant procedures $(25 \%)$, or did not specify $(12.5 \%)$. Fewer nonstate parties had appropriate procedures in place $(15.8 \%)$, while most reported no relevant procedures $(73.7 \%)$, or did not specify $(10.5 \%)$.

Given the rapid expansion of migration within Asia-Pacific, this finding highlights an important gap in assessment services for access to higher education programs, or for recognition of qualifications to seek employment opportunities subject to domestic laws and regulations. The implications for information sharing and mobility governance will be explored further in the following section.

(3) National Information Centres in Asia-Pacific - The Tokyo Convention (Article VIII) requires each party to provide relevant information on their national higher education system and qualifications, as well as to take adequate measures to develop and maintain an NIC (Table 3). While the nature of the NIC may vary based on national specifications, each party agreed to appoint a member to the regional NIC network to promote mutual understanding and transparency in Asia-Pacific.

While the founding eight members of APNNIC reported on their progress, more than $2 / 3(68 \%)$ of nonstate parties have not yet established NICs. This area of information provision is an important gap in the Asia-Pacific region. Establishing an NIC is not required prior to ratification of the Tokyo Convention, but the planning and budgeting for such implementation mechanisms is fundamental to the Convention principles and for competent recognition authorities to understand as part of their formal responsibilities for implementation.

Nonstate parties were also asked about their readiness to ratify and implement the Tokyo Convention (Table 4). Among national respondents $(n=19)$, one reported no intent for their country to ratify the Convention $(5.3 \%)$. Most reported desired but no progress made

Table 2.

Assessment services available for refugee and persons in a refugee-like situation
Parties to the Tokyo Convention

(1) Yes: 5/8 (62.5\%)

(2) No, there are no relevant procedures: $2 / 8$ $(25.0 \%)$

(3) Other*: $1 / 8(12.5 \%)$

Note(s): *Other, not specified

Source(s): Authors
Non-state parties to the Tokyo Convention
(1) Yes: $3 / 19(15.8 \%)$
(2) No, there are no relevant procedures: $14 / 19$ $(73.7 \%)$
(3) Other*: 2/19 (10.5\%) 
( $n=7 ; 36.8 \%)$, or background planning is underway $(n=9 ; 47.4 \%)$. Surprisingly few $(n=2$; $10.5 \%$ ) reported that their countries is ready and close to ratification or that final approval is pending $(n=0)$. After nine years since the revised convention was adopted in 2011 in Tokyo, the level of readiness to ratify remains low. The estimated timeline for further ratifications ranged from an additional six months to more than five years. This is in line with the 1983 Convention, which to date has 21 parties after more than 35 years of implementation. Ratification and implementation challenges vary by country, yet some patterns emerged.

Common barriers reported in the country reports included a lack of awareness about benefits to ratification $(n=7)$; lack of administrative capacity $(n=5)$, ratification is not urgent $(n=4)$, time constraints $(n=4)$, and challenges with internal procedures $(n=3)$. Respondents could select more than one barrier. A key challenge to realizing the potential of the Tokyo Convention is aligning national and regional mechanisms to promote fair and transparent recognition of qualifications in Asia-Pacific.

At national level, the Tokyo Convention requires the assurance of competent recognition authorities and the establishment of an NIC. At regional level, Committee Sessions are held regularly to monitor the Convention and APNNIC. In practice, this landscape is constantly shifting in the Asia-Pacific region due to staff turnover and a relatively new network of NICs launched in 2019. With regard to the development and maintenance of an NIC, related needs in Asia-Pacific include: provide technical support on ratification procedures $(n=15)$, capacity building or resource mobilization on implementation $(n=12)$, raise the visibility of the benefits of ratification $(n=11)$, cooperation opportunities for regional knowledge sharing $(n=10)$, networking and peer learning $(n=10)$, and no needs $(n=2)$.

The Tokyo Convention provides a formal governance structure to monitor gaps and improve mobility governance. In this way, NICs uphold and assist the practical implementation of the Tokyo Convention. With a critical mass of NICs, the new APNNIC network will meet annually to set priorities for implementation of the Tokyo Convention. Ratification of the Convention is

\begin{tabular}{|c|c|}
\hline Articles of the Tokyo Convention on NIC & Implementation by parties \\
\hline $\begin{array}{l}\text { Development and maintenance of an NIC that will provide higher education } \\
\text { information (Article VIII.3) }\end{array}$ & $\begin{array}{l}100 \% \text { have relevant structures } \\
\text { in place }\end{array}$ \\
\hline Establish a network of NICs to uphold and assist the practical & APNNIC established 20 \\
\hline implementation (Article IX.3.1) & September 2019 \\
\hline Appoint a member to the network (Article IX.3.2) & $100 \%$ appointed a member \\
\hline $\begin{array}{l}\text { Meet annually in plenary session (article IX.3.3), in conjunction with } \\
\text { ordinary sessions of the Tokyo convention committee (Rules of procedure } \\
\text { 3.3) }\end{array}$ & Agreed (Ongoing) \\
\hline Collect relevant information from the parties relating to academic & Collected annually by UNESCO \\
\hline recognition and mobility $(A$ & \\
\hline
\end{tabular}

Source(s): Authors

\section{Tokyo \\ Convention on recognition}

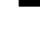


IJCED

23,3

168

required to appoint more NICs and help to build a viable network for effective information sharing and troubleshooting on recognition issues in the Asia-Pacific. It is equally important to empower UNESCO Bangkok to serve as Secretariat for continuous improvement and capacity building throughout the region. This is needed to ensure the Tokyo Convention is inclusive of all Member States and diverse stakeholder interests, which UNESCO Bangkok monitors.

There are many emerging opportunities to further strengthen policy coherence of recognition based on acquired competencies, quality assurance and mutual recognition of qualifications. In this regard, international recognition relies on quality assurance to underpin academic mobility and cross-border employability. This can help secure recognition of a country's qualifications across the Asia-Pacific, or to facilitate recognition of Asia-Pacific qualifications in the home country. The following section explores how these core principles and implementation mechanisms in Asia-Pacific align with the forthcoming Global Convention.

\subsection{Monitoring alignment of the Tokyo and Global Conventions}

Given that today more than half of all students going abroad are studying outside their home regions, UNESCO established a drafting committee for a global convention on recognition in consultation with Member States. Following a General Conference decision in March 2016 (38/Resolution 12) and rigorous consultative process, UNESCO Member States adopted the Global Convention on the Recognition of Qualifications concerning Higher Education at the 40th Session of the General Conference in November 2019. The Global Convention requires 20 Parties before its entry into force and to date has only been ratified by Nicaragua and Norway. Upon its entry into force, the coordinated actions between the Tokyo and Global Convention committees will be increasingly important to ensure value for stakeholders and for mobility governance worldwide.

The degree of national alignment of the Tokyo and forthcoming Global Convention texts is important to review as part of the evolution of recognition principles and monitoring mechanisms for collaborative governance. There are many similarities and complementarities to the Tokyo and Global Conventions texts, yet also relatively little data available on what the core principles may mean in practice given gaps in reporting and limitations on formal stakeholder engagement [2]. While the regional and global conventions are meant to be complementary, how the two conventions will work in practice is not yet clear given their early stages of development and that the Global Convention is not yet in force.

At higher levels, the objectives of the two conventions are mutually supportive, including to facilitate mobility through international cooperation, provide an inclusive framework for fair recognition, respect domestic laws and institutional autonomy (i.e. does not mean automatic recognition), and requests parties to specify how to recognize. Similarly, the core principles of the Tokyo and Global Conventions are shared, including preserving an individual right to assessments; transparent, fair, non-discriminatory and timely assessments; decisions based on quality information from competent authorities; appeal mechanisms; recognition may lead to further study, use of academic title, and employment.

The Global Convention includes new principles for qualification recognition that are not in the Tokyo Convention. In terms of core principles and purposes, the Global Convention seeks to eliminate fraudulent practices and ensure that recognition should affordable based on local practices (i.e. availability of information), which is not included in the Tokyo Convention. To assess the alignment of the two conventions, the following examples explore three core articles on substantial difference, qualifications recognition for refugees and displaced persons, and the role of NICs.

(1) Substantial difference - In both the Tokyo and Global Conventions, provisions on substantial difference aim to promote access to higher education, partial studies, and the fair assessment of higher education qualifications. In both conventions, concepts 
about what constitutes substantial difference aim to minimize unreasonable barriers to recognition, and holds the decision maker (i.e. the competent recognition authority) accountable for demonstrating substantial difference. The top three reported examples of what may constitute a substantial difference among state parties of the Tokyo Convention, include that an institution or program is not accredited $(n=7$ / 8 ); has different access requirements $(n=7 / 8)$, or there are substantial differences related to online studies $(n=5 / 8)$. For the first time, the Global Convention will define substantial difference and provide partial recognition where there is substantial difference [3] Further research is needed to assess gaps and implications for these new areas of recognition, including assessments of new credentials and qualifications offered through non-traditional modes, and factors such as a greater focus on quality assurance and use of learning outcomes.

(2) Qualifications recognition for refugees and displaced persons - The Tokyo and Global Conventions require procedures to assess qualifications and prior learning, subject to the party's laws and regulations, establish processes for when there are no documents as evidence, ensure fair and timely assessments, and promote inclusive and equitable access to quality higher education and lifelong learning. The Global Convention takes a step further and promotes recognition of partial studies (in addition to prior learning and completed qualifications) and recognition to access further higher education programs (e.g. postgraduate study).

(3) Role of information provision and NICs - Providing information to support recognition decisions is a fundamental requirement for both Conventions, including promoting the role of NICs. Beyond providing access to authoritative information about the higher education system (i.e. providing support for other recognition authorities, institutions or applicants in a timely manner), the Global Convention has a more expansive view than the Tokyo Convention. The Global Convention parties will share materials for good practices, encourage use of technology for easy access to information, and ensure institutions provide information to applicants and recognition authorities free of charge. In addition to the role of NICs at regional level, the Global Convention will also promote participation in existing regional NIC networks or create new networks, strengthen inter-regional cooperation and share information, build capacity and provide technical support to parties.

There are important similarities and complementarities to the Tokyo and Global Conventions, and international collaboration is essential to understand these issues in practice. The two conventions provide the practical framework and regulations for recognition and a path to promote access to quality higher education. The following section elaborates on UNESCO's work program to ensure effective collaboration.

\subsection{Building capacity for inclusive governance in the Asia-Pacific}

Mutual accountability is central to achieving SDG4 based on partnerships and guiding principles for inclusive and participatory policy dialogue (UNESCO, 2015a). However, accountability itself involves multiple sub-dimensions, including transparency, liability, controllability, responsiveness and responsibility (Koppell, 2005). Taken together, effective monitoring of diverse outcomes and accountabilities can also inform relevant areas for collaboration (Teter, 2020). To promote mutual accountability among diverse stakeholders, UNESCO has a unique role in international higher education, including to address gaps and opportunities in cross-border mobility governance. At operational levels, UNESCO's work program for standard-setting instruments is based on five core activities from 2015 to 2021: 
IJCED

23,3

(1) Implementation - providing technical support and opportunities for capacity building and resource mobilization;

(2) Monitoring implementation - developing procedures and addressing challenges faced by Member States;

(3) Ratification - offering country-relevant technical support and expertise;

(4) Cooperation - facilitating regional knowledge sharing, networking and peer learning;

(5) Visibility - ensuring understanding and visibility of the Convention's benefits through awareness raising and information sharing (UNESCO, 2015b).

To implement this work plan, a growing number of projects and donors play a central role in advancing UNESCO's mission and mandate for higher education in Asia-Pacific, including the Japanese Funds-in-Trust and Republic of Korea Funds-in-Trust, which provide project-based support for capacity building of NICs in developing countries. International development partners such as the Asian Development Bank (ADB), European Commission, and World Bank are also key stakeholders and partners. Together with UNESCO as an associate partner, a network supported in part by the European Commission will provide technical and financial assistance through the Regional Cooperation in the Field of Recognition among Asian Countries (RecoASIA) project. The joint work program with international partners includes a focus on developing countries to:

(1) Analyze cross-border mobility flows and preparing national reports on recognition practices with partner countries in Europe and Asia;

(2) Reinforce the mandate and functioning of NICs at government level;

(3) Reinforce competencies related to the internationalization of higher education and recognition issues within countries in the Asia-Pacific;

(4) Establish rules and guidelines for evaluating non-traditional, cross-border and distance learning institutions and analyzing the impacts of diploma mills;

(5) Strengthen quality assurance and recognition procedures in higher education institutions;

(6) Promote fair recognition of qualifications of refugees, displaced persons and persons in a refugee-like situation;

(7) Communicate and disseminate results in Europe and Asia (RecoASIA, 2021).

These development efforts are part of long-term work plans and collaborative efforts to build stakeholder capacity to deliver quality education and fair recognition of qualifications based on learning outcomes. Over two decades ago in the Delors (1996), an international commission outlined similar aspirations, saying: "the extension of learning throughout life will require consideration of new procedures for certification that take account of acquired competences" (p. 139). This statement from 1996 was echoed in SDG4. This is important because it speaks to longstanding needs and growing challenges to recognize new qualification types, achieved both online and in person. More than two decades after the far-reaching Delors Report, the higher education community is advancing towards its ideals.

\section{Conclusion and the way forward}

To move forward, fair and transparent procedures for recognition should be shared and discussed to build consensus, including around the three areas highlighted in this paper what constitutes substantial difference, how to assess qualifications from vulnerable 
learners, and the need to address gaps in authoritative information from NICs in the AsiaPacific region. Given the impacts of COVID-19, learning inequalities are a top concern. Fairness and transparency are needed to ensure recognition of nontraditional modes of delivery such as online or blended learning.

In practice, governance of the Tokyo Convention is in the hands of State Parties based on a shared commitment to the Convention text and the Committee's rules of procedure. As discussed, stakeholder engagement in the Tokyo Convention as a forum for collaborative governance is limited. Currently, the Bureau of the Tokyo Convention Committee is not required to consult stakeholders, but may choose to invite non-governmental organizations active in the field of recognition. To establish a multi-stakeholder approach based on collaborative governance, the commitment of governments is needed.

As reported, meaningful engagement of nonstate actors based on shared decision-making are fundamental components of collaborative governance (Ansell and Gash, 2008), and effective monitoring of outcomes and accountabilities (Teter, 2020). The potential and feasibility for a multi-stakeholder approach to collaboration, including to systematically engage higher education institutions, quality assurance agencies, industry and students are important areas for future research related to monitoring outcomes and complex accountabilities of the Tokyo Convention itself. These questions are critical for mutual accountability and to ensure the Committee achieves its true purpose to strengthen geographical, cultural, educational and economic ties (UNESCO, 2011). These findings are important given the current governance structure of the Tokyo Convention does not currently lend itself to open participation or openly accessible information sharing (e.g. national-level reports on substantial differences, the status of NICs, or how the rights of vulnerable learners are protected in the Asia-Pacific region). While this paper introduced a survey instrument as well as baseline data on the Tokyo Convention's implementation, more in-depth work on national and regional-level monitoring is needed.

Based on the current implementation status of the Tokyo Convention there are a number of important areas for further research and development to enhance accountability and promote fair and transparent recognition throughout the region:

(1) Flexible learning - Enabled by the Tokyo Convention, recognition of diverse pathways and modes of learning is increasingly important for life and decent work. Fair recognition based on learning outcomes is critical given growing demand for flexible and diversified higher education programs.

(2) Inclusive networks - The Tokyo Convention on recognition is limited without an inclusive and representative APNNIC for the region. What are the key benefits of ratification for diverse local stakeholders in the Asia-Pacific? How will developing countries gain the needed administrative capacity to ratify and implement the regional and global conventions?

(3) Listening to end-users - The end-users of qualifications are lifelong learners and industry, including entrepreneurs. New communication channels and mutual accountability mechanisms are needed to better monitor and understand mobility governance in practice. How can outcomes and accountabilities be monitored through collaborative governance platforms such as the Tokyo Convention Committee?

(4) Global outlook - The principles that govern mobility are evolving in a more global and inclusive framework. The Tokyo Convention Committee must also define its relationship with the Global Convention, including how the Asia-Pacific region will be represented (i.e. as the world's most mobile region), and how it will learn from diverse stakeholders through open and inclusive communications. How will the Tokyo Convention continue to evolve to meet the needs of its regional and global partners?
Tokyo
Convention on recognition 
IJCED

23,3

Additional ratifications and full implementation of the Tokyo Convention in the AsiaPacific are key factors for a viable and inclusive future for collaborative governance. Effective collaboration is not possible without an operational commitment to global issues, including gender equality and Africa, two of UNESCO's cross-cutting priorities. The Global Convention is a step towards strengthening an inclusive approach to recognition and offers the Tokyo Convention Committee an opportunity to become a regional network with global influence. Difficult questions remain when many Member States and UNESCO lack the necessary financial resources and administrative capacity to foster full implementation of the Tokyo Convention. Resource mobilization and enhancing collaborative governance, when effectively managed, represent a way forward to build regional capacity of recognition authorities, provide needed technical expertise, and ensure the achievement of SDG4.

More fundamentally, a new era must draw on UNESCO's normative focus and a humanistic lens for societal transformation. These ideals are embodied in normative instruments as well as flagship reports such as the Faure Report (1972) and the Delors (1996). Building on these foundations, an International Commission will engage diverse stakeholder networks as part of UNESCO's Futures of Education initiative. The futures of cross-border mobility and fair recognition of qualifications are a means to explore the public value of physical and virtual mobility. A vital task will be to include and respond to diverse stakeholder perspectives and to the growing complexity of work, lifelong learning and sustainable living.

\section{Notes}

1. As of February 2021, there were eleven Parties to the Tokyo Convention on recognition (Afghanistan, Australia, China, Fiji, Holy See, Japan, Mongolia, New Zealand, Republic of Korea, Russian Federation and Turkey), with others expected to follow shortly.

2. There are a number of formal restrictions on observing the Tokyo Convention Committee, including that representatives of governmental and non-governmental organizations active in the field of recognition in the Asia-Pacific Region may be invited to attend meetings of the Committee as observers by a decision of the Bureau in consultation with Secretariat at UNESCO (Tokyo Convention, Rules of Procedure).

3. Substantial differences are significant differences between the foreign qualification and the qualification of the State Party which would most likely prevent the applicant from succeeding in a desired activity, such as, but not limited to, further study, research activities, or employment opportunities (UNESCO, 2019a).

\section{References}

Alam, G.M. (2019), "Quality assurance for private universities in Bangladesh: a quest for specialised institutional governance, management and regulatory mechanism", International Journal of Comparative Education and Development, Vol. 22 No. 1, pp. 1-15, doi: 10.1108/IJCED-012019-0006.

Altbach, P.G. and Knight, J. (2007), "The internationalization of higher education: motivations and realities", Journal of Studies in International Education, Vol. 11 Nos 3-4, pp. 290-305.

Ansell, C. and Torfing, J. (2016), Handbook on Theories of Governance, Edward Elgar Publishing, Cheltenham.

Ansell, C. and Gash, A. (2008), "Collaborative governance in theory and practice", Journal of Public Administration Research and Theory, Vol. 18 No. 4, pp. 543-571, doi: 10.1093/jopart/mum032.

Bryson, J.M., Crosby, B.C. and Stone, M.M. (2015), "Designing and implementing cross sector collaborations: needed and challenging", Public Administration Review, Vol. 75 No. 5, pp. 647-663, doi: 10.1111/puar.12432. 
Delors, J. (1996), "Learning: the treasure within", report to UNESCO of the International Commission on Education for the Twenty-first Century, UNESCO, Paris, available at: https:/unesdoc. unesco.org/ark:/48223/pf0000109590?posInSet=12\&queryId=f9897ad1-e31b-4acf-a2d8e64997ad28ab.

Emerson, K., Nabatchi, T. and Balogh, S. (2011), "An integrative framework for collaborative governance", Journal of Public Administration Research and Theory, Vol. 22 No. 1, pp. 1-29, doi: 10.1093/jopart/mur011.

European Consortium for Accreditation in Higher Education (2008), The Benefits of Mutual Recognition of Accreditation and Quality Assurance Decisions, The Hague, pp. 28-31.

Faure, E. (1972), Learning to Be: The World of Education Today and Tomorrow, UNESCO, Paris.

Hou, A.Y. (2012), "Mutual recognition of quality assurance decisions on higher education institutions in three regions: a lesson for Asia”, Higher Education, Vol. 64, pp. 911-926, doi: 10.1007/s10734012-9536-1.

Hou, A.Y., Morse, R. and Wang, W. (2017), "Recognition of academic qualifications in transnational higher education and challenges for recognizing a joint degree in Europe and Asia”, Studies in Higher Education, Vol. 42 No. 7, pp. 1211-1228, doi: 10.1080/03075079.2015.1085010.

Jarvis, D.S.L. and Mok, K.H. (Eds) (2019), Transformations in Higher Education Governance in Asia Policy, Politics and Progress, Springer Nature.

Knight, J. (2007), "Cross-border Higher Education: issues and implications for quality assurance and accreditation", Higher Education in the World 2007: Accreditation for Quality Assurance: What is at Stake?, Global University Network for Innovation, New York, NY: Palgrave Macmillan, pp. 134-146.

Koppell, J.G.S. (2005), "Pathologies of accountability: ICANN and the challenge of "multiple accountabilities disorder”, Public Administration Review, Vol. 65 No. 1, pp. 94-108, doi: 10.1111/j. 1540-6210.2005.00434.x.

Lee, M.N.N. (2012), "Regional cooperation in higher education in Asia and the Pacific", Asian Education and Development Studies, Vol. 1 No. 1, pp. 18-23, doi: 10.1108/20463161211194432.

Marginson, S. (2018), "Higher education, economic inequality and social mobility: implications for emerging East Asia”, International Journal of Educational Development, Vol. 63, pp. 4-11.

Morse, R.S. (2011), "The practice of collaborative governance", Public Administration Review, Vol. 71 No. 6, pp. 953-957, doi: 10.1111/j.1540-6210.2011.02448.x.

RecoASIA (2021), “About the project”, RecoASIA - Regional Cooperation in the Field of Recognition Among Asian Countries, available at: www.recoasia.eu (accessed 30 January 2021).

Teter, W. (2020), "Fostering problem driven collaboration in a development context: the ASEAN study of health workforce governance", Asia Pacific Journal of Public Administration, Vol. 42 No. 2, pp. 89-110, doi: 10.1080/23276665.2020.1753222.

UNESCO (1983), "Regional convention on the recognition of studies, diplomas and degrees in higher education in Asia and the Pacific (1983 Bangkok convention)", available at: http://portal.unesco. org/en/ev.php-URL_ID =13523\&URL_DO=DO_TOPIC\&URL_SECTION=201.html.

UNESCO (2011), "Asia-Pacific regional convention on the recognition of qualifications in higher education (2011 Tokyo convention)” , available at: http://portal.unesco.org/en/ev.php-URL_ $\mathrm{ID}=48975 \&$ URL_DO=DO_TOPIC\&URL_SECTION $=201 . \mathrm{html}$.

UNESCO (2015a), "Education 2030 - Incheon declaration and framework for action. Towards inclusive and equitable quality education and lifelong learning for all", available at: http://unesdoc. unesco.org/images/0024/002432/243278e.pdf.

UNESCO (2015b), Strategy on Standard-Setting Instruments in the Field of Education (2015-2021), UNESCO, Paris, available at: ED/PLS/EDP/2015/01.

UNESCO (2018b), Seoul Statement. The Tokyo Convention - A New Era for Mobility and Internationalisation of Higher Education in the Asia-Pacific through Qualifications Recognition, UNESCO, Bangkok.

Tokyo
Convention on
recognition 
IJCED

23,3

UNESCO (2019a), "Global convention on the recognition of qualifications concerning higher

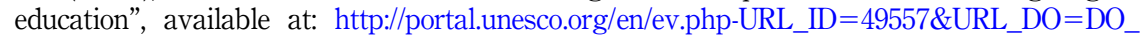
TOPIC\&URL_SECTION=201.html.

UNESCO (2019b), Inaugural Statement - the Asia-Pacific Network of National Information Centres (APNNIC), UNESCO Bangkok, Bangkok.

UNESCO (2020), Global Education Monitoring Report: Inclusion and Education - All Means All, UNESCO, Paris.

Woodhouse, D. (1998), "Quality assurance in higher education: the next 25 years", Quality in Higher Education”, Vol. 4 No. 3, pp. 257-273, doi: 10.1080/1353832980040306.

Woodhouse, D. (2008), "International perspectives on the benefits of mutual recognition - a global perspective”, European Consortium for Accreditation”, in Higher Education (Ed.), The Benefits of Mutual Recognition of Accreditation and Quality Assurance Decisions, The Hague, pp. 28-31.

\section{Further reading}

Kim, G.J. and Teter, W. (2018), "Closing the gaps - what does an equity agenda look like in AsiaPacific?", in Kennedy, K.J. and Lee, J.C.K. (Eds), Routledge International Handbook of Schools and Schooling in Asia, Routledge, Abingdon, pp. 15-27.

UN Global Compact for Migration (2018), "Global compact for safe, orderly and regular migration. Intergovernmentally negotiated and agreed outcome", available at: https://refugeesmigrants.un. org/migration-compact.

UNESCO Recommendation concerning the Status of Higher-Education Teaching Personnel (1997), available at: http://portal.unesco.org/en/ev.php-URL_ID=13144\&URL_DO=DO_TOPIC\&URL_ SECTION=201.html.

UNESCO (2018a), Guidelines on Developing and Strengthening Qualifications Frameworks in Asia and the Pacific - Building a Culture of Shared Responsibility, UNESCO, Bangkok, 978-92-9223-603-8.

UNESCO (2018c), Paper Commissioned for the 2019 Global Education Monitoring Report, Migration, Displacement and Education: Building Bridges, Not Walls, UNESCO, Paris.

UNESCO Institute for Statistics (2019), "Analysis by UNESCO Bangkok's assessment, information system, monitoring and Statistics (AIMS), Asia-Pacific regional office of the UNESCO institute for statistics", available at: http://uis.unesco.org/ (accessed 2 September 2019).

\section{Corresponding author}

Wesley R. Teter can be contacted at: eisd.bgk@unesco.org

For instructions on how to order reprints of this article, please visit our website:

www.emeraldgrouppublishing.com/licensing/reprints.htm

Or contact us for further details: permissions@emeraldinsight.com 